\title{
EMERGING AND SCRIPTED ROLES IN COMPUTER-SUPPORTED COLLABORATIVE LEARNING
}

This is a post-print of an article submitted for consideration in the Computers in Human Behavior (C) 2010 Elsevier.

Personal use of this manuscript is permitted. Permission from Elsevier must be obtained for any other commercial purpose.

This article may not exactly replicate the published version, due to editorial changes and/or formatting and corrections during the final stage of publication. Interested readers are advised to consult the published version which can be found at:

http://www.sciencedirect.com/science/article/pii/S0747563209001368

doi: $\{10.1016 /$ j.chb.2009.08.006 \}

Please refer this manuscript as:

Strijbos, J. W., \& Weinberger, A. (2010). Emerging and scripted roles in computer-supported collaborative learning. Computers in Human Behavior, 26, 491-494. 
Running head: EMERGING AND SCRIPTED ROLES IN CSCL

Emerging and scripted roles in computer-supported collaborative learning

\author{
Jan-Willem Strijbos* \\ Leiden University
}

Armin Weinberger

University of Twente

${ }^{*}$ Correspondence can be sent to Jan-Willem Strijbos, Leiden University, Faculty of Social and Behavioural Sciences, Centre for the Study of Learning and Instruction, P. O. Box 9555, 2300 RB, Leiden, The Netherlands. Phone: ++31-71-5274048, Fax: ++31-71-5273619, Email: jwstrijbos@fsw.leidenuniv.nl 


\begin{abstract}
Emerging and scripted roles pose an intriguing approach to analysing and facilitating CSCL. The concept of emerging roles provides a perspective on how learners structure and self-regulate their CSCL processes. Emerging roles appear to be dynamic over longer periods of time in relation to learners' advancing knowledge, but are often unequally distributed in ad hoc CSCL settings, e.g. a learner being the 'typist' and another being the 'thinker'. Empirical findings show that learners benefit from structuring or scripting CSCL. Scripts can specify roles and facilitate role rotation for learners to equally engage in relevant learning roles and activities. Scripted roles can, however, collide with emerging roles and therefore need to be carefully attuned to the advancing capabilities of the learners.
\end{abstract}

Keywords: roles, scripted roles, emerging roles, collaborative learning, CSCL 
Emerging and scripted roles in computer-supported collaborative learning

Computer-Supported Collaborative Learning (CSCL) is becoming more and more popular at all educational levels; and especially in higher education (Strijbos, Kirschner, \& Martens, 2004). Through use of different tools for constructing, representing, and mediating arguments between peers, CSCL can facilitate learners to elaborate their knowledge in peer discussions and acquire multiple perspectives on a topic (Andriessen, Baker, \& Suthers, 2003;

Weinberger, 2008). CSCL environments provide the opportunity for a shift in the traditional roles of teachers and learners in classroom instruction, in favour of knowledge building communities in which students assume more control over their learning processes. In Knowledge Forum, for instance, learners play the roles of scientists by constructing scientific arguments, examining various problem solutions, contributing the solutions to a communal database, and accessing, reviewing, and operating on contributions of their peers (Scardamalia \& Bereiter, 1996).

CSCL was regarded to foster equal participation (Dubrovsky, Kiesler, \& Sethna, 1991) and to facilitate advanced principles of learning and instruction disclosing new roles for learners (Koschmann, Myers, Feltovich, \& Barrows, 1994). Evidence has been gathered supporting the view that CSCL can facilitate learning - especially when some form of instructional support or structure is introduced that defines the roles and activities learners are supposed to engage in (Fischer, Kollar, Haake, \& Mandl, 2007; Järvelä, Häkkinen, Arvaja, \& Leinonen, 2004; Kirschner \& Kreijns, 2005; Schellens \& Valcke, 2006; Strijbos, De Laat, Martens, \& Jochems, 2005).

\section{Perspectives on roles in CSCL research}

The role concept has had a major influence on our understanding of how people interact, the expectations they have towards each other, and their functions in a group or community (Biddle, 1986). Roles can be defined as more or less stated functions or responsibilities that 
guide individual behaviour and regulate group interaction (Hare, 1994). Roles can promote individual responsibility and group cohesion (Mudrack \& Farrell, 1995) as well as positive interdependence and individual accountability (Brush, 1998), which are central support factors in collaborative learning arrangements (Forsyth, 1999; Slavin, 1996). Roles can also facilitate group members' awareness of overall group performance and of peer contributions (Mudrack \& Farrell, 1995; Strijbos, Martens, Jochems, \& Broers, 2004, 2007) and are most relevant for distributing, coordinating, and integrating sub-tasks to attain a shared goal.

During the past five years the role concept has become a promising construct for analysing and facilitating CSCL. There are roughly two perspectives regarding roles in CSCL: the emerging roles perspective that focuses on the roles that participants develop spontaneously in support of their collaborative learning activities, and the scripted roles perspective that focuses on how the collaborative learning process can be facilitated by structuring and prescribing roles and activities to the learners (Kollar, Fischer, \& Hesse, 2006).

The emerging roles perspective

The emerging roles perspective emphasises that learners structure and self-regulate their CSCL processes and CSCL researchers have realised that the analysis of emerging roles is important for our understanding of students' individual contribution and interaction patterns with fellow group members (De Laat, 2006; De Laat \& Lally, 2004, Pilkington \& Walker, 2003; Strijbos et al., 2005; Waters \& Grasson, 2007). For example the detailed exploratory study by De Laat (2006) highlighted the impact of the task on how students structure their collaborative activities, and revealed that students develop a personal style (emerging roles) during their online learning activities. De Laat also showed that students developed a social and meta-cognitive awareness of each other's learning styles, which facilitates students in structuring and regulating group learning.

Emerging roles are mostly static during a single collaborative session or task, but they can 
also develop dynamically over longer periods of time in relation to the learners' advancing knowledge and / or their collaborative learning experiences. One intriguing issue is how the learners implicitly distribute roles during the collaborative learning session or task, without challenging or rotating roles once they have emerged (Dillenbourg, 2002; Soller, Goodman, Linton, \& Gaimari, 1998). For instance, dyads working in front of one computer have been observed to spontaneously develop and enact the roles of 'typists' and 'thinkers' throughout the collaborative session (Bruhn, 2000). In small groups, roles can often emerge in response to unequal workload (Strijbos, Martens et al., 2007).

Recent advancements in the automated detection of roles aid our understanding of emerging roles. Marcos, Martínez, Dimitriadis and Anguita (2006) applied social network analysis (SNA) to an authentic CSCL course and detected four roles: teacher-guide, teachercollaborator, isolated-learner and coordinator-learner. In a second phase they triangulated the SNA findings with questionnaires, focus groups and classroom observations, to identify and validate the role changes during the collaborative process as revealed by SNA. In a similar vein, Welser, Gleave, Fischer and Smith (2007) used SNA to identify, distinguish and predict the role of 'answer people' in large Usenet newsgroups. Yet, irrespective of their ability to identify role behaviour, any form of automated and dynamic detection remains at a surface level: participants are central or not, participate often or not, etc. The methods do not touch upon the content of specific messages and how this content may reflect - perhaps even explain - specific behaviour and interactive patterns that some participants exert consistently throughout the collaboration.

\section{The scripted roles perspective}

The scripted roles perspective emphasises the need for instructional support, specifically designed to improve both collaborative learning processes and outcomes (Dillenbourg 2002; Fischer et al., 2007). In CSCL it is widely acknowledged that the spontaneous collaboration 
through standard CSCL software does not necessarily lead learners to play the functional and complementing roles that foster group discussion, knowledge sharing and argumentation (Jermann, Soller, \& Lesgold, 2004; Pfister \& Oehl, 2009). Scripts specify and externalise the roles expected from the learners before or during collaboration. Consequently, scripted roles are assigned to learners by teachers or educational designers to structure the collaborative process. Computer-supported collaboration scripts have been defined as explicit suggestions to learners that specify, sequence, and distribute roles and activities over a group of learners in CSCL environments (Kobbe et al., 2007; Kollar et al., 2006; Weinberger, 2008). A script can specify those roles that are deemed relevant and efficient and also facilitate role rotation for learners to equally engage in the relevant roles and activities.

The scripted approach in CSCL builds on early approaches to structure and induce specific interaction patterns in collaborative learning scenarios. O’Donnell and Dansereau (1992) introduced a script for supporting dyads in reading and text comprehension that specified and rotated the roles of summariser and critic per paragraph. The Jigsaw procedure (Aronson, Blaney, Stephan, Sikes, \& Snapp, 1978) can also be regarded as a predecessor to scripting, in which learners gather knowledge in expert groups and pass on this expert knowledge in basic groups. Whereas in the original scripted collaboration approach face-to-face learners without computer support had to be trained to follow prescriptions of the scripts for more time than was actually foreseen for collaboration, computer-supported collaboration scripts that are implemented in the computer interface need little to no time for prior training (Weinberger, 2008).

Scripted roles are functional in the sense that they specify the activities that are considered relevant for the collaborative process and knowledge building, and that learners rarely engage in spontaneously, such as giving explanations, constructing arguments, or resolving conflicts productively. Often scripted roles - especially those designed for primary education - consist 
of a single job, task or duty (see Johnson, Johnson, \& Johnson-Holubec, 1992; Kagan, 1994). Scripts can specify a large variety of roles (Weinberger, Stegmann, Fischer, \& Mandl, 2007), for instance, scripted roles can be content-oriented or process-oriented (Strijbos, Martens et al., 2004; Weinberger, Ertl, Fischer, \& Mandl, 2005). A content-oriented role, for example the role of summariser, focuses directly on the learning content and can lead to higher levels of knowledge construction (see Schellens, Van Keer, \& Valcke, 2005; De Wever, Van Keer, Schellens, \& Valcke, 2007). A process-oriented role, for example the role of the project planner, fosters individual responsibility and coordination, and affects learning indirectly (Strijbos, Martens et al., 2004, 2007).

Emerging or scripted perspectives: incommensurable or productive tensions?

The emerging and scripted role perspectives are both being applied in CSCL research with different foci on analysing and facilitating learners' interactions. Irrespective of some shared characteristics, both perspectives developed independently with some noteworthy differences as shown in Table 1.

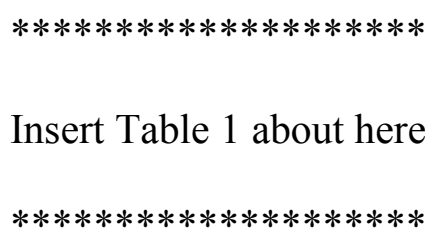

In relation to efficient and effective collaborative learning experiences, both perspectives carry some inherent risks. The emerging roles perspective may lead learners in collaborative arrangements to focus on tasks they already can handle rather than acquiring new knowledge by taking on tasks that pose a challenge for them. Such an 'expert role' approach may have a positive effect on the amount of information shared (Stasser, Stewart, \& Wittenbaum, 1995), but can also inhibit students' learning.

Some roles in CSCL appear to provide more cognitive learning opportunities than others (e.g., the summariser role; Schellens \& Valcke, 2006), which renders a static role distribution 
problematic for the individual learner. Although the risk of unequal opportunity for cognitive benefits argues in favour of rotating scripted roles, the risk for over-scripting collaboration (Dillenbourg, 2002) needs to be monitored. Scripts - purposefully - interrupt and restructure natural interaction and problem solving processes and this may collide with emerging roles (or internal scripts; Kollar, Fischer, \& Slotta, 2007), especially when students already know how to effectively engage in specific activities and distribute the relevant roles. One approach to mitigate over-scripting could be that scripted roles are adapted to emerging roles, i.e. scripts can be faded in to introduce and / or (re)distribute roles or faded out for learners to continuously increase self-regulation of their learning processes. Once students have internalised a role they can then enact the role seemingly spontaneous, and this might appear as an emerging role during an unscripted CSCL activity. Scripts and their roles therefore need to be carefully attuned to the advancing capabilities of the learners.

\section{Contributions on emerging and scripted roles}

Clearly, both research on emerging and scripted roles need to be taken into account and linked with each other to identify potential for synergy or unwanted interaction effects between the two types of roles. The contributions in this special issue aim to bridge the two perspectives, acknowledging the parallels as well as tensions and providing the groundwork for mutual exchange and development. The contributions comprise of a conceptual framework on roles in CSCL contexts (Strijbos \& De Laat, this issue), two studies on scripted roles (Weinberger, Stegmann, \& Fischer, this issue; De Wever, Van Keer, Schellens, \& Valcke, this issue) and two studies on emerging roles (Sarmiento \& Shumar, this issue; Jahnke, this issue).

Strijbos and De Laat (this issue) present a conceptual framework that systematically describes a number of recurrent roles as stances in CSCL along three dimensions, namely group size, orientation, and effort. Based on qualitative analyses of two asynchronous online 
courses, they identified eight roles: Captain, Over-rider, Free-rider, Ghost, Pillar, Generator, Hanger-on, and Lurker. This set of roles aims to assist teachers in moderating online courses, including CSCL of different group sizes, and also to evaluate students' participation as well as foster self-evaluation.

The contribution of Weinberger, Stegmann, and Fischer (this issue) is a quantitative study on scripted roles underlining how CSCL can outperform individual computer-supported learning only if supported by a script. Moreover, the script effect on content-based roles, i.e. the distribution of the task within a group, is compared to the range of task aspects individual learners can cover. The script problematises task performance and reduces task aspects that can be covered. Whereas collaborative learners can compensate for this reduction, individual learners' task performance is strongly slowed down by the script.

De Wever, Van Keer, Schellens and Valcke (this issue) contribute a quantitative study on when to introduce scripted roles (i.e., starter, summariser, moderator, theoretician, and source searcher), and their influence on the quality of knowledge construction. Their results suggest to script roles early on during the collaboration and gradually fading script support out, rather than fading-in script support at a later stage in the CSCL process.

Sarmiento and Shumar (this issue) take a positioning theory perspective on roles and participation when qualitatively analysing how positional change within an online mathematical inquiry learning community (The Math Forum) develops in parallel to the advancement of student knowledge and capabilities. The engagement of the students is being analysed in relation to their peers as well as in relation to affordances of the online environment.

Jahnke (this issue) also presents a qualitative field study of an online knowledge building community and the community development over the course of eight years. Within that time frame, Jahnke shows how the community develops from informal to formal by analysing the 
changing social roles and structures and their functions for knowledge building.

The contributions are then discussed in two commentaries. Spada (this issue) provides an insightful discussion on how the contributions aid our understanding of the effect of roles on student learning. Hoadley (this issue) adopts a design perspective on roles in CSCL arguing that roles may act as a boundary-object for seemingly incommensurable theoretical and methodological perspectives.

The contributions to this special issue clearly illustrate that linking the two perspectives of emerging and scripted roles can foster research on the internalisation of scripted roles and their spontaneous enactment, as well as research on fading scripts in and out according to the spontaneously emerging roles. In this respect, the recent advances in automatic analysis of collaborative processes (e.g., Marcos et al., 2006; Rosé, Wang, Cui, Arguello, Stegmann, Weinberger, \& Fischer, 2008) comprise a fruitful direction in attuning emerging and scripted roles and thereby enhance the $\mathrm{L}$ in CSCL. 
Emerging and scripted roles in CSCL 1212

Acknowledgements

The guest editors would like to thank the reviewers for their contribution to this special issue. 


\section{References}

Andriessen, J., Baker, M., \& Suthers, D. (2003). Arguing to learn: Confronting cognitions in computer-supported collaborative learning environments. Dordrecht: Kluwer.

Aronson, E., Blaney, N., Stephan, C., Sikes, J., \& Snapp, M. (1978). The jigsaw classroom. Beverly Hills, CA: Sage.

Biddle, B. J. (1986). Recent development in role theory. Annual Review of Sociology, 12, 6792.

Bruhn, J. (2000). Förderung des kooperativen Lernens über Computernetze [Facilitation of cooperative learning via computer networks]. Frankfurt am Main: Lang.

Brush, T. A. (1998). Embedding cooperative learning into the design of integrated learning systems: Rationale and guidelines. Educational Technology Research \& Development, 46, $5-18$.

De Laat, M. F. (2006). Networked learning. Unpublished doctoral dissertation, Utrecht University, Utrecht, The Netherlands.

De Laat, M., \& Lally, V. (2004). It's not so easy: Researching the complexity of emergent participant roles and awareness in asynchronous networked learning discussions. Journal of Computer Assisted Learning, 20, 165-171.

De Wever, B., Van Keer, H., Schellens, T., \& Valcke, M. (2007). Applying multilevel modelling to content analysis data: Methodological issues in the study of role assignment in asynchronous discussion groups. Learning \& Instruction, 17, 436-447.

De Wever, B., Van Keer, H., Schellens, T., \& Valcke, M. (this issue). Roles as a structuring tool in online discussion groups: The differential impact of different roles on social knowledge construction. Computers in Human Behavior, xx, $\mathrm{xx}-\mathrm{xx}$. 
Dillenbourg, P. (2002). Over-scripting CSCL: The risks of blending collaborative learning with instructional design. In P. A. Kirschner (Ed.), Three worlds of CSCL: Can we support CSCL? (pp. 61-91). Heerlen: Open University of the Netherlands.

Dubrovsky, V. J., Kiesler, S., \& Sethna, B. N. (1991). The equalization phenomenon: status effects in computer-mediated and face-to-face decision-making groups. Human Computer Interaction, 6, 119-146.

Fischer, F., Kollar, I., Mandl, H., \& Haake, J. M. (Eds.) (2007). Scripting computersupported collaborative learning: Cognitive, computational and educational perspectives. New York: Springer.

Forsyth, D. R. (1999). Group dynamics (3rd ed.). Belmont: Wadsworth.

Hare, A. P. (1994). Types of roles in small groups: A bit of history and a current perspective. Small Group Research, 25, 443-448.

Jahnke, I. (this issue). Dynamics of social roles in a knowledge management community. Computers in Human Behavior, xx, xx-xx.

Järvelä, S., Häkkinen, H., Arvaja, M., \& Leinonen, P. (2004). Instructional support in CSCL. In J. W. Strijbos, P. A. Kirschner \& R. L. Martens (Eds.), What we know about CSCL: And implementing it in higher education (pp.115-139). Boston, MA: Kluwer.

Jermann, P., Soller, A., \& Lesgold, A. (2004). Computer support for CSCL. In J. W. Strijbos, P. A. Kirschner, \& R. L. Martens (Eds.), What we know about CSCL: And implementing it in higher education (pp. 141-166). Boston, MA: Kluwer.

Johnson, D. W., Johnson, R. T., \& Johnson-Holubec, E. (1992). Advanced cooperative learning. Edina: Interaction Book Company.

Kagan, S. (1994). Cooperative learning. San Juan Capistrano: Kagan Cooperative Learning. 
Kirschner, P.A., \& Kreijns, K. (2005). The sociability of computer-mediated collaborative learning environments: Pitfalls of social interaction and how to avoid them. In R. Bromme, F. Hesse, \& H. Spada (Eds.), Barriers and biases in computer-mediated knowledge communication: And how they may be overcome (pp. 169-192). Dordrecht: Kluwer.

Kobbe, L., Weinberger, A., Dillenbourg, P., Harrer, A., Hämäläinen, R., \& Fischer, F. (2007). Specifying computer-supported collaboration scripts. International Journal of Computer-Supported Collaborative Learning, 2, 211-224.

Kollar, I., Fischer, F., \& Hesse, F. W. (2006). Collaboration scripts - A conceptual analysis. Educational Psychology Review, 18, 159-185.

Kollar, I., Fischer, F., \& Slotta, J. D. (2007). Internal and external scripts in computersupported collaborative inquiry learning. Learning \& Instruction, 17, 708-721.

Koschmann, T. D., Myers, A. C., Feltovich, P. J., \& Barrows, H. S. (1994). Using technology to assist in realizing effective learning and instruction: A principled approach to the use of computers in collaborative learning. Journal of the Learning Sciences, 3, 227-264.

Marcos, J. A., Martínez, A., Dimitriadis, Y., \& Anguita, R. (2006). Interaction analysis for the detection and support of participatory roles in CSCL. In Y. Dimitriades, I. Zigurs, \& E. Gómez-Sánchez (Eds.), Proceedings of the 12th International CRIWIG workshop: Groupware: Design, implementation, and use (pp. 155-162). Berlin: Springer.

Mudrack, P. E., \& Farrell, G. M. (1995). An examination of functional role behaviour and its consequences for individuals in group settings. Small Group Research, 26, 542-571.

O’Donnell, A. M., \& Dansereau, D. F. (1992). Scripted cooperation in student dyads: A method for analysing and enhancing academic learning and performance. In R. HertzLazarowitz \& N. Miller (Eds.), Interaction in cooperative groups: The theoretical anatomy of group learning (pp. 120-144). New York: Cambridge University Press. 
Pfister, H.-R., \& Oehl, M. (2009). The impact of goal focus, task type and group size on synchronous net-based collaborative learning discourses. Journal of Computer Assisted Learning, 25, 161-176.

Pilkington, R. M., \& Walker, S. A. (2003). Facilitating debate in networked learning: Reflecting on online synchronous discussion in higher education. Instructional Science, 31, 41-63.

Rosé, C., Wang, Y. C., Cui, Y., Arguello, J., Stegmann, K., Weinberger, A., \& Fischer, F. (2008). Analyzing collaborative learning processes automatically: Exploiting the advances of computational linguistics in computer-supported collaborative learning. International Journal of Computer-Supported Collaborative Learning, 3, 237-271.

Sarmiento, J. W., \& Shumar, W. (this issue). Boundaries and roles: Positioning and social location in the Virtual Math Teams (VMT) online community. Computers in Human Behavior, $x x, \mathrm{xx}-\mathrm{xx}$.

Scardamalia, M., \& Bereiter, C. (1996). Computer support for knowledge-building communities. In T. Koschmann (Ed.), CSCL: Theory and practice of an emerging paradigm (pp. 249-268). Mahwah, NJ: Erlbaum.

Schellens, T., \& Valcke, M. (2006). Fostering knowledge construction in university students through asynchronous discussion groups. Computers \& Education, 46, 349-370.

Schellens, T., Van Keer, H., \& Valcke, M. (2005). The impact of role assignment on knowledge construction in asynchronous discussion groups: A multilevel analysis. Small Group Research, 36, 704-745.

Slavin, R. (1996). Research for the future. Research on cooperative learning and achievement: What we know, what we need to know. Contemporary Educational Psychology, 21, 43-69. 
Soller, A., Goodman, B., Linton, F., \& Gaimari, R. (1998). Promoting effective peer interaction in an intelligent collaborative learning environment. In B. P. Goettl, H. M. Halff, C. L. Redfield, \& V. J. Shute (Eds.), Proceedings of the fourth international conference on intelligent tutoring systems (pp. 186-195). Berlin: Springer.

Stasser, G., Stewart, D. D., \& Wittenbaum, G. M. (1995). Expert roles and information exchange during discussion: The importance of knowing who knows what. Journal of Experimental Social Psychology, 31, 244-265.

Strijbos, J. W., \& De Laat, M. F. (this issue). Developing the role concept for computersupported collaborative learning: An explorative synthesis. Computers in Human Behavior, $x x, \mathrm{xx}-\mathrm{xx}$.

Strijbos, J. W., De Laat, M. F., Martens, R. L., \& Jochems, W. M. G. (2005). Functional versus spontaneous roles during CSCL. In T. Koschmann, D. Suthers, \& T. W. Chan (Eds.), Computer supported collaborative learning 2005: The next 10 years! (pp. 647656). Mahwah, NJ: Lawrence Erlbaum Associates.

Strijbos, J. W., Kirschner, P. A., \& Martens, R. L. (Eds.). (2004). What we know about CSCL: And implementing it in higher education. Boston, MA: Kluwer.

Strijbos, J. W., Martens, R. L., Jochems, W. M. G., \& Broers, N. J. (2004). The effect of functional roles on group efficiency: Using multilevel modeling and content analysis to investigate computer-supported collaboration in small groups. Small Group Research, 35, 195-229.

Strijbos, J. W., Martens, R. L., Jochems, W. M. G., \& Broers, N. J. (2007). The effect of functional roles on perceived group efficiency during computer-supported collaborative learning: A matter of triangulation. Computers in Human Behavior, 23, 353-380.

Waters, J., \& Grasson, S. (2007, January). Distributed knowledge construction in an online community of inquiry. Paper presented at the 40th HICSS conference, Hawaii, USA. 
Weinberger, A. (2008). CSCL scripts: Effects of social and epistemic scripts on computersupported collaborative learning. Berlin: VDM.

Weinberger, A., Ertl, B., Fischer, F., \& Mandl, H. (2005). Epistemic and social scripts in computer-supported collaborative learning. Instructional Science, 33, 1-30.

Weinberger, A., Stegmann, K., Fischer, F., \& Mandl, H. (2007). Scripting argumentative knowledge construction in computer-supported learning environments. In F. Fischer, H. Mandl, J. Haake, \& I. Kollar (Eds.), Scripting computer-supported communication of knowledge: Cognitive, computational and educational perspectives (pp. 191-211). New York: Springer.

Weinberger, A., Stegmann, K., \& Fischer, F. (this issue). Learning to argue online: Scripted groups surpass individuals (unscripted groups do not). Computers in Human Behavior, xx, $\mathrm{XX}-\mathrm{XX}$

Welser, H. T., Gleave, E., Fisher, D., \& Smith, M. (2007). Visualizing the signatures of social roles in online discussion groups. Journal of Social Structure, 8(2). Retrieved July 9, 2007, from http://www.cmu.edu/joss/content/articles/volume8/Welser 
Table 1. Comparison of the emerging and scripted perspective along six characteristics.

Emerging roles

Tacit: identified after the collaboration.

Spontaneous student-initiated role-taking.

Close to personal skill and / or competency.

Role execution is intrinsically motivated and triggered by group dynamics.

Typically unequal and relatively static role distribution depending on personal needs and competency to 'read' the collaborative process.

Execution of role behaviour continues for as long the role is considered productive and/or relevant by the role-taker and / or fellow group members.
Designed: identified prior to collaboration.

Deliberate instructor-initiated role-taking.

Can be deliberately assigned to deviate from personal skill and / or competency to maximise the learning potential.

Role execution is extrinsically motivated and triggered by explicit instructions.

Equal role distribution, achieved through the number of roles and / or role rotation during consecutive collaborative sessions or tasks.

Execution of role behaviour is consistent in a collaborative session or task; unless rotation is explicitly designed by the instructor. 